\title{
A ATUAÇÃO DA SOCIEDADE CIVIL NO PROCESSO BRASILEIRO DE REFÚGIO
}

\author{
The Role of Civil Society in Screening Asylum in Brazil
}

Flávia Rodrigues de Castro*

Resumo. O processo brasileiro de determinação do status de refugiado é governado pelo Comitê Nacional para Refugiados (CONARE) - órgão administrativo que julga a credibilidade dos solicitantes de refúgio e tem poder de decisão sobre os casos - com participação ativa da sociedade civil. O presente artigo propõe analisar a atuação da sociedade civil neste processo através das práticas epistêmicas responsáveis por julgar quem pode ser categorizado como refugiado. Para tanto, será utilizada aqui uma abordagem teórica que enfatiza a possibilidade de produção de injustiças epistêmicas nas análises de credibilidade.

Palavras-chave: Sociedade Civil; refúgio; credibilidade; injustiça epistêmica.

Abstract. The refugee status determination (RSD) process in Brazil is governed by the National Committee for Refugees (CONARE) - the administrative body responsible for assessing the credibility of asylum seekers and deciding all asylum cases in the country - with the active participation of civil society. This paper aims to analyze the role of civil society in this process through the epistemic practices responsible for judging who can be categorized as a refugee. In order to do this, a theoretical approach that emphasizes the production of epistemic injustices in credibility analysis will be used here.

Keywords: Civil Society; asylum; credibility; epistemic injustice.

Professora de Relações Internacionais (Unilasalle). Rio de Janeiro, RJ - Brasil. E-mail: flaviacastro. uff@gmail.com. Orcid: 0000-0001-9951-5271. 


\section{Introdução}

O processo brasileiro de determinação do status de refugiado é atravessado pela atuação complexa e múltipla de uma série de atores que compõem o Comitê Nacional para Refugiados (CONARE) ${ }^{1}$, órgão responsável por analisar a credibilidade dos solicitantes de refúgio, criado em 1997 pela lei nacional 9.474. A maior inovação desta lei foi, precisamente, o estabelecimento de um órgão multiministerial responsável por avaliar e decidir todos os casos de solicitação de refúgio no Brasil, bem como a presença consolidada da sociedade civil no processo decisório (Facundo, 2017; Jubilut, 2007). Tal presença se dá através da representação da Cáritas, instituição que ocupa espaço permanente no Comitê desde sua criação e desenvolve seu programa de atendimento a solicitantes e refugiados. Tendo em mente o papel destacado desta representação, com poder de voz e voto nas decisões sobre os casos de refúgio, a análise aqui desenvolvida será realizada em torno da participação da Cáritas-Rio no processo, considerando sua posição de representante titular da sociedade civil no CONARE. Embora tal instituição não tenha sido eleita pela sociedade civil, nem diretamente nomeada pela lei 9.474, não ocupe posição de maneira rotativa no Comitê (nem oficialmente definitiva) e não tenha relação direta de prestação de contas com a sociedade civil, a estrutura formal do órgão aponta diretamente para sua participação enquanto representante titular da sociedade civil. É preciso, dessa maneira, que o leitor leve em consideração tais questões diante do recorte da presente análise ${ }^{2}$.

Busco lançar luz aqui sobre o processo brasileiro de refúgio a partir da atuação da sociedade civil nas práticas de determinação do status de refugiado. Para tanto, utilizo como arcabouço teórico a discussão em torno do conceito

1 O CONARE é composto por: Ministério da Justiça e Segurança Pública, que o preside; Ministério das Relações Exteriores, que ocupa a vice-presidência; Ministério da Educação, Ministério da Saúde, Ministério do Emprego e Trabalho; Departamento da Polícia Federal; Cáritas/RJ e Cáritas/SP como representantes da sociedade civil, titular e suplente, respectivamente; e o Alto Comissariado das Nações Unidas para Refugiados (ACNUR), que possui direito a voz, sem voto. A Defensoria Pública da União tem status de membro consultivo perante o CONARE e o Instituto de Migrações e Direitos Humanos (IMDH) participa como membro observador.

2 Embora seja incômodo atribuir a apenas uma instituição o lugar de 'sociedade civil', o questionamento desta atribuição parece indicar a necessidade de um debate mais amplo e aprofundado sobre nossos modelos de representatividade e, mais do que isso, sobre o processo de nomeação, rotatividade e prestação de contas no que tange à instituição que ocupa tal lugar no CONARE. Da mesma forma, torna-se crucial ressaltar que, também no âmbito do Comitê, o trabalho dos advogados e assistentes de proteção da Cáritas é representado por um membro titular e um membro suplente, nominalmente identificados. Durante as entrevistas, tornou-se evidente a existência de discrepâncias entre as opiniões dos advogados e assistentes de proteção que participam das discussões coletivas no Comitê e os membros que possuem direito ao voto na reunião decisória. Ainda assim, a decisão final dos membros (titular e suplente) torna-se decisão em nome da sociedade civil. Não se trata, portanto, de discutir aqui questões de culpabilidade, mas de ressaltar também a importância de um debate sobre representação no CONARE - e, possivelmente, na própria Cáritas. 
de injustiça epistêmica, desenvolvido inicialmente por Miranda Fricker (1999, 2003, 2006, 2007, 2008). Procuro, assim, discutir o processo do refúgio por elegibilidade no Brasil, bem como o papel da sociedade civil no mesmo, tendo como foco a possibilidade de produção de injustiças epistêmicas em uma "economia da credibilidade" (Fricker, 2007). Ainda que a presente análise esteja voltada à atuação da sociedade civil, cabe indicar aqui que não deve ser atribuída à Cáritas a responsabilidade exclusiva pela produção de injustiças no processo. Tendo em vista a complexidade inerente aos processos decisórios em âmbito multiministerial, torna-se fundamental analisar também a possibilidade de uma injustiça epistêmica estrutural, reproduzida pelos diferentes atores que compõem o CONARE em suas práticas diárias³.

A análise desenvolvida neste artigo está baseada em uma série de entrevistas com oficiais de elegibilidade e atores da sociedade civil e de organizações governamentais, no Rio de Janeiro, São Paulo e Brasília. Foram conduzidas cinquenta e duas entrevistas no total, no período entre julho de 2018 e abril de 2019. Por questões de confidencialidade, todos os nomes utilizados aqui são pseudônimos e a menção aos cargos ocupados pelos entrevistados só é realizada em casos de funcionários vinculados ao Ministério da Justiça e Segurança Pública.

O desenvolvimento do artigo se dá da seguinte maneira: a primeira seção aborda as práticas de injustiça epistêmica em uma "economia da credibilidade" (Fricker, 2007). Em outras palavras, procuro expor inicialmente o arcabouço teórico utilizado na análise, enfatizando a dimensão testemunhal da injustiça epistêmica e o papel da credibilidade neste cenário. Na segunda seção busco explicitar as dinâmicas e procedimentos do refúgio por elegibilidade no Brasil, enfatizando suas principais etapas e modos de determinação do status de refugiado. Por fim, a última seção traz uma análise crítica das práticas do refúgio por elegibilidade a partir da atuação da sociedade civil no processo. Tendo como base as entrevistas realizadas, procuro refletir sobre a produção de injustiças epistêmicas no espaço das trocas testemunhais com os solicitantes de refúgio, assim como em espaços coletivos deliberativos que excluem a participação desses sujeitos.

\section{As práticas de injustiça epistêmica em uma economia da credibilidade}

O conceito de injustiça epistêmica foi desenvolvido inicialmente pela autora Miranda Fricker (1999, 2003, 2006, 2007, 2008) a partir de discussões acerca das nossas "práticas epistêmicas", isto é, das atividades voltadas à produção e transmissão do conhecimento, bem como à criação de significados ou conceitos

Tal análise escapa aos objetivos deste artigo e é desenvolvida em trabalho distinto, como tese de doutorado, intitulada "Refúgio e Injustiça Epistêmica: uma Análise a partir do Brasil". 
que permitiriam fazer sentido de experiências sociais e compartilhá-las com outros. Em seu livro, intitulado Epistemic Injustice: Power \& the Ethics of Knowing, Fricker propõe a existência de um tipo essencialmente epistêmico de injustiça, caracterizado por um "mal feito a alguém especificamente em sua capacidade como um sujeito do conhecimento" (Fricker, 2007, p. 1).

A injustiça epistêmica conforme entendida por Fricker é composta por duas dimensões distintas, mas em grande medida interligadas: a injustiça testemunhal e a injustiça hermenêutica. A primeira é definida pela autora como algo que "ocorre quando um preconceito leva um ouvinte a conceder um nível esvaziado de credibilidade para a palavra daquele que narra", enquanto a segunda "ocorre em um estágio anterior, quando um gap nos recursos interpretativos coletivos coloca alguém em desvantagem quando se trata de fazer sentido de suas experiências sociais" (Fricker, 2007, p. 1). A injustiça testemunhal é produzida, então, a partir da atuação de uma série de preconceitos e estereótipos que fazem com que haja um ataque à autoridade epistêmica daquele que narra ou testemunha algo e a sua capacidade enquanto sujeito do conhecimento. Já a injustiça hermenêutica é produzida a partir de uma participação desigual nas práticas pelas quais os significados sociais são gerados, o que pode resultar na produção de conceitos inadequados para fazer sentido de experiências sociais - ou, ainda, em uma não produção desses conceitos.

Para os fins da presente análise, o artigo trabalhará especificamente com a dimensão testemunhal da injustiça epistêmica, enfatizando as práticas que se desenvolvem na chamada "economia da credibilidade" (Fricker, 2007), ou seja, nos julgamentos de credibilidade que ocorrem em trocas testemunhais. Os casos centrais deste tipo de injustiça ocorrem a partir da existência de déficits de credibilidade que resultam de disfunções baseadas em preconceitos no espaço da troca testemunhal.

Apesar da perspectiva de Fricker desempenhar papel central nesta análise e, claro, no próprio campo de debates em torno do conceito de injustiça epistêmica, parece relevante colocar em tensão a ideia de que apenas um déficit de credibilidade deve ser compreendido como um potencial indicativo de injustiça testemunhal. Dessa maneira, procuro inserir aqui a crítica elaborada por José Medina (2011) acerca da falta de atenção ao papel que um excesso de credibilidade também pode desempenhar na produção de injustiças epistêmicas do tipo testemunhal. Segundo este autor, é fundamental ter em mente a relação íntima estabelecida entre déficits e excessos de credibilidade no contexto de produção de injustiças. Em outras palavras, não seria possível ignorar a possibilidade de que ao atribuir excessos de credibilidade para determinados sujeitos estaríamos também produzindo 
déficits de credibilidade para outros. Esta noção será central para a análise do processo brasileiro de refúgio, conforme veremos mais adiante.

Ao falarmos sobre uma "economia da credibilidade" seria necessário considerar o que Medina chama de uma natureza interativa e uma qualidade comparativa: implicitamente, ser julgado crível significa ser visto como mais, menos ou igualmente crível em relação a outros (Medina, 2011). Assim, haveria o que o autor denomina de privilégio epistêmico nos casos de atribuições excessivas de credibilidade, implicando "o tratamento imerecido de um sujeito epistêmico que recebe comparativamente mais confiança do que outros sujeitos receberiam sob as mesmas condições" (Medina, 2011, p. 20). A partir da contribuição do autor, a injustiça epistêmica (testemunhal) passa a ser compreendida como algo que é produzido não apenas a partir da ausência de reconhecimento epistêmico, sob a forma de déficits de credibilidade, mas também desde uma posição de privilégio epistêmico, entendido como um excesso imerecido de credibilidade. Para Medina (2011, p. 21), "essas duas fontes de injustiça epistêmica não funcionam de maneira independente, mas estão intimamente interligadas". Considero a perspectiva do autor sobre privilégio epistêmico e excessos de credibilidade uma contribuição fundamental para analisarmos casos específicos de produção de injustiças testemunhais, conforme buscarei demonstrar neste artigo.

$\mathrm{Na}$ economia da credibilidade analisada por Fricker (2007) também ganha papel de destaque a atuação dos chamados preconceitos identitários. Embora a autora reconheça a possibilidade de que déficits de credibilidade sejam causados em função de "erros inocentes" do julgamento humano, seu enfoque recai sobre a existência de preconceitos que fazem com que a injustiça testemunhal esteja conectada a outros tipos de injustiça, assumindo um caráter sistemático. Em outras palavras: "quando um preconceito gera uma injustiça testemunhal, essa injustiça está sistematicamente conectada com outros tipos de injustiça existente ou potencial" (Fricker, 2007, p. 27). Segundo a autora, o caso central de seu debate passa a ser, então, a injustiça testemunhal sistemática, uma vez que esta revelaria como a injustiça epistêmica está inserida em um padrão mais amplo de (in) justiça social. Neste contexto, o preconceito atuaria de maneira intimamente relacionada à atuação de estereótipos, vistos como amplas associações entre um grupo e um atributo, produzindo um "compromisso cognitivo com alguma generalização empírica sobre determinado grupo social ('mulheres como seres intuitivos')" (Fricker, 2007 , p. 31). Haveria, assim, a produção de generalizações empíricas não confiáveis sobre sujeitos de grupos sociais já marginalizados.

A partir de suas análises, Fricker ressalta o caráter subjetivo dos julgamentos de credibilidade, afastando uma dimensão puramente racional da compreensão acerca de quem pode ser considerado um sujeito crível. 
Conforme vimos anteriormente, a economia da credibilidade descrita pela autora está baseada em uma série de imagens preconceituosas que se tornam resistentes a evidências, aproximando-se do âmbito do irracional. Haveria, nesse sentido, a produção de imagens distorcidas de determinados sujeitos, fazendo com que seus interlocutores não sejam capazes de atribuir credibilidade às narrativas. Fricker exemplifica em sua obra a partir de casos de negros e mulheres como tipos sociais, isto é: a concepção desses sujeitos a partir de ideias sociais pré-determinadas faz com que haja uma distorção no julgamento de sua credibilidade e "essa operação de poder identitário controla quem pode transmitir conhecimento para quem e, assim, quem pode ganhar conhecimento de quem" (Fricker, 2007, p. 90).

Apesar do afastamento da ideia de que julgamentos de credibilidade são baseados em aspectos puramente racionais, a ênfase de Fricker permanece sobre a atuação de preconceitos e estereótipos nas trocas testemunhais. Uma ampliação deste debate se dá através das contribuições de Gloria Origgi (2012), estimulando reflexões necessárias sobre outros mecanismos que podem afetar os julgamentos de credibilidade - e que emergem como relevantes para a análise realizada aqui, conforme veremos na última seção. Assim, segundo Origgi (2012), seria possível ampliar o entendimento sobre a injustiça testemunhal ao levarmos em conta a atuação de outros mecanismos para além do preconceito - e que também ressaltam o aspecto não-racional das trocas testemunhais. Nesse sentido, o preconceito seria apenas um dos fatores que podem ajudar a produzir quadros de injustiça epistêmica. A autora propõe, então, uma análise detalhada sobre como os julgamentos de credibilidade envolvem a noção de confiança - a qual não emerge apenas de uma postura intelectual, racional, mas também de uma emoção: do sentimento de confiança (Origgi, 2004, 2012). Origgi oferece, dessa maneira, uma perspectiva teórica sobre diferentes fontes de confiança que podem impactar julgamentos de credibilidade, como inferência sobre a confiabilidade do sujeito e de sua narrativa, normas sociais internalizadas em deferência à autoridade, reações emocionais, compromissos morais, dentre outras.

O campo de debates teóricos em torno do conceito de injustiça epistêmica foi desenvolvido a partir de uma série de críticas e questionamentos em articulação com as propostas originais de Fricker em obras variadas ${ }^{4}$. Embora não seja possível, nem desejável, que eu me detenha aqui sobre o estado da arte deste campo de discussões, é fundamental ter em mente os esforços analíticos de ampliação do escopo da injustiça epistêmica. Por ora, contudo, torna-se fundamental reafirmar o interesse do presente artigo em

4 Para mais detalhes acerca das discussões neste campo, ver: Alcoff (2010), Anderson (2012), Bailey (2018), Dotson (2011), Fricker (1999, 2003, 2006, 2008, 2010), Hookway (2010), Kwong (2015), Marsh (2011), Riggs (2010, 2012). 
analisar possibilidades de produção de injustiças epistêmicas testemunhais no campo do refúgio no Brasil, as quais podem ser causadas tanto por déficits quanto por excessos de credibilidade, sendo impactadas pela atuação não só de preconceitos e estereótipos, como também por reações emocionais que influenciam em quem confiamos e por quê.

\section{Refúgio por elegibilidade no Brasil: em busca do solicitante Crível}

Após a entrada no país, um dos primeiros passos que deve ser tomado por quem deseja solicitar refúgio é o preenchimento do formulário de solicitação de refúgio. O documento contém perguntas que vão desde informações básicas para identificação do solicitante e dos seus familiares, passando por questões acerca da sua formação escolar e atuação profissional, até questionamentos mais específicos a respeito da solicitação de refúgio, como os motivos para a saída do país de origem ou residência habitual, por exemplo. Apesar de soar como documentação protocolar inicial, o formulário de refúgio pode ser entendido como essencial para diferentes estágios do processo de solicitação, uma vez que todas as informações contidas no documento serão checadas posteriormente, na condução das entrevistas e nas análises do mérito do pedido de refúgio.

A próxima etapa fundamental no processo é a realização da chamada entrevista de elegibilidade. É neste encontro testemunhal que o solicitante é novamente confrontado com as perguntas relacionadas à sua vida pregressa e aos motivos para solicitar refúgio no Brasil, com a busca pela confirmação dos fatos narrados anteriormente em formulário - ainda que o espaço temporal entre tais etapas possa levar anos, como usualmente ocorre no país. As entrevistas são descritas pelos funcionários do Comitê como um momento ritualístico que passa pela apresentação geral das etapas do processo de elegibilidade, pela reafirmação da confidencialidade e sigilo referente às informações compartilhadas pelo solicitante, chegando à parte crucial de questionamento a respeito do pedido de refúgio.

Tendo por base a entrevista de elegibilidade, um parecer é emitido pela coordenação do CONARE, recomendando o deferimento ou indeferimento da solicitação de refúgio. O parecer de elegibilidade é produzido, então, pelo Ministério da Justiça e Segurança Pública, usualmente pelo oficial que realizou a entrevista - ainda que esta não seja a norma em todos os casos (Jensen, 2018). O documento contém informações básicas sobre o solicitante e sua entrevista, assim como detalhes a respeito das razões para a solicitação e da análise de credibilidade. Esta análise é parte fundamental do parecer, uma vez que é com base nela que a recomendação do documento é desenvolvida, alegando as razões para deferimento ou indeferimento do pedido. 
A parte mais relevante do parecer é, assim, a análise de credibilidade ${ }^{5}$, a qual também é percebida como "um dos aspectos mais desafiadores do processo decisório no âmbito do refúgio" (HHC, 2013, p. 7). Embora não seja o objetivo deste artigo discutir os critérios envolvidos na análise de credibilidade das solicitações de refúgio, cabe mencionar aqui que há geralmente uma divisão importante em duas categorias amplas: credibilidade interna e externa $(\mathrm{HHC}$, 2013; Sweeney, 2009). De maneira breve, podemos entender a credibilidade interna como sendo uma análise das próprias afirmações do solicitante, isto é, da consistência e coerência da sua narrativa e das possíveis provas que são trazidas ao processo. Já a credibilidade externa encontra-se relacionada à comparação entre a narrativa do solicitante e os fatos gerais conhecidos sobre o seu país de origem ou de residência habitual. Por ora, e sem entrar em maiores detalhes, é possível afirmar que a análise de credibilidade é parte crucial não só dos pareceres, como do processo de elegibilidade como um todo, orientando as discussões nos espaços coletivos que compõem as próximas etapas do processo: o chamado Grupo de Estudos Prévios (GEP) e a plenária do CONARE.

As sessões do chamado GEP são realizadas mensalmente em Brasília, de forma a permitir o debate entre os membros do Comitê dos casos agendados para a próxima plenária do órgão. É importante destacar aqui o caráter não-obrigatório das reuniões do GEP, entendidas pelos membros do Comitê como voltadas ao debate técnico das solicitações de refúgio, fornecendo as bases para a decisão final a ser tomada na plenária do CONARE. Dessa maneira, embora o GEP ocorra de maneira regular, suas dinâmicas e realização dependem da vontade dos membros do Comitê, os quais reforçam que o momento decisório permanece sendo a reunião oficial do plenário do órgão.

Se a solicitação de refúgio for indeferida, o solicitante possui o prazo de quinze dias para interposição do recurso administrativo, a contar da data de recebimento da notificação. O recurso pressupõe, assim, um pedido para nova avaliação do caso por parte do mesmo Comitê que julgou o indeferimento, o qual pode modificar seu parecer inicial ou ratificá-lo. A decisão é, então, final.

\section{A Sociedade Civil no processo e a injustiça epistêmica}

A fim de analisar a atuação da sociedade civil no refúgio por elegibilidade, tendo como fio condutor o conceito de injustiça epistêmica, proponho uma reflexão a partir do ritual de preenchimento do formulário de solicitação de

5 Discutir a análise de credibilidade no universo do refúgio constitui, por si só, um trabalho exploratório extenso e demandante que fugiria ao escopo do presente artigo. Assim. para uma visão mais detalhada sobre análise de credibilidade, ver: Alexander (1999), Cameron (2010), Cohen (2001), Gibb e Good (2014), Good (2007), Gorlick (2002), Griffiths (2012), Kagan (2003, 2006), Magalhães (2014, 2016), Rousseau et alii (2002), Sales (2002), Saltsman (2014), Souter (2011), Weston (1998). 
refúgio, passando pelas práticas das entrevistas de elegibilidade e, por fim, chegando aos julgamentos de credibilidade. Neste último ponto, buscarei ressaltar a distinção realizada entre "casos fortes e fracos" e a caracterização do GEP como o espaço dos "técnicos do refúgio".

No que diz respeito aos aspectos que podem determinar, em algum grau, as possibilidades de injustiça epistêmica, e conforme já exposto anteriormente, o presente artigo trabalha com três elementos, a saber: déficits ou excessos de credibilidade, que menosprezam a narrativa dos solicitantes e fortalecem uma posição de privilégio epistêmico dos atores responsáveis pelas avaliações dos casos (Medina, 2011); preconceitos e estereótipos que podem implicar em conduta discriminatória, ainda que de maneira inconsciente (Anderson, 2012; Fricker, 2007; Hookway, 2010); reações emocionais que indicam a forte presença de critérios subjetivos como forma de determinar a confiabilidade no que tange às narrativas dos sujeitos (Origgi, 2004, 2012).

O ritual de preenchimento do formulário de solicitação de refúgio é uma prática epistêmica fundamental no processo, conforme vimos na seção anterior. Da fala dos atores entrevistados, especialmente dos funcionários da Cáritas-Rio, emerge a importância da orientação adequada, uma vez que o solicitante de refúgio nem sempre possui conhecimento sobre como responder as perguntas que constam no extenso formulário. Manuela ${ }^{6}$, da Cáritas-Rio, me contou um pouco sobre essa dinâmica, relatando um caso específico em que o solicitante, ao se deparar com a pergunta 'o que aconteceria se você retornasse ao seu país de origem ou residência habitual?', respondeu 'nada'. Assim, segundo ela:

Teve uma pessoa que escreveu "nada", eu acho que foi um sírio, eu acho que era um sírio e ele escreveu "nada", e aí a gente foi perguntar para ele: como assim, não ia acontecer nada? A resposta dele foi tão interessante, ele falou assim: nada, porque no meu país não tem nada, não tem escola, não tem trabalho, não tem farmácia, não tem nada. (Manuela, Cáritas-Rio, grifo meu)

A prática de orientação realizada pelos funcionários da Cáritas-Rio ${ }^{7}$ faz com que o estranhamento inicial diante da narrativa do solicitante seja logo substituído pela busca por uma adaptação à linguagem burocrática do processo, de modo a facilitar a compreensão dos outros atores envolvidos na determinação do status de refugiado. Assim, em casos como esse, é feita uma orientação para que o solicitante complete sua narrativa, desenvolvendo e

\footnotetext{
Todos os nomes utilizados neste artigo são pseudônimos.

7 Cabe ressaltar aqui a ênfase do artigo sobre a atuação da Cáritas-Rio, tendo em vista o recorte da análise a respeito da participação da sociedade civil nas práticas da elegibilidade. Com isso não quero dizer, entretanto, que a possibilidade de (re)produção de injustiças epistêmicas se restrinja à instituição, desconsiderando a importância dos outros atores que compõem a estrutura do CONARE.
} 
detalhando seus temores. Uma história de refúgio não permite, então, "nada" como resposta, porque conforme nos diz Facundo (2017, p. 237), é preciso "cavar no sujeito".

A constante busca pela adaptação das narrativas pode gerar um bloqueio à circulação de ideias críticas (Fricker, 2007), fazendo com que o teor indignado da resposta do solicitante seja perdido. Na busca pela conversão da vida em documento, perde-se aquilo de mais singular que o sujeito tinha a dizer, em seu modo específico de narrar sua compreensão da experiência da violência como um espaço significativo de vazio ou ausência (de oportunidades, de educação, de trabalho). Nos termos de uma injustiça epistêmica, o conhecimento que seria transmitido ao interlocutor não é recebido. Ganha destaque aqui a posição epistemicamente privilegiada (Medina, 2011) dos atores responsáveis por determinar quais os estilos de narrativa, as formas de evidência e os modos de compartilhar o conhecimento seriam mais adequados nesta troca testemunhal (Carel, Kidd, 2014), o que podemos ver refletido na busca pela adaptação dos testemunhos à linguagem do processo de refúgio.

O ritual de preenchimento do formulário traz à tona as dificuldades dos sujeitos em fazer sentido de suas experiências e, ao mesmo tempo, encaixá-las no quadro do refúgio por elegibilidade. Teríamos, nesse sentido, o estabelecimento de práticas que demandam que o conhecimento do solicitante seja transmitido aos atores desse sistema, porém com a exigência de um enquadramento à linguagem legal-burocrática do refúgio. A importância do conhecimento do solicitante é facilmente substituída pela expertise da orientação sobre o enquadramento da sua narrativa à lei do refúgio, relegando os solicitantes ao papel de "analfabetos funcionais". Conforme me contou Joana, da Cáritas-Rio, "por mais que a gente explique, algumas coisas são difíceis da pessoa entender porque às vezes são analfabetos funcionais, então as pessoas conseguiam ler, mas não entendiam as perguntas, então eu tinha que explicar cada uma das perguntas".

Em relação à credibilidade, a existência de preconceitos relacionados à dimensão da competência pode fazer com que o outro seja visto como ignorante ou estúpido (Anderson, 2012). É preciso ter em mente que as análises de credibilidade não são realizadas apenas com base na dimensão da sinceridade, mas também da competência (Fricker, 2007). No caso específico levantado aqui, a narrativa do solicitante é vista como incompetente, isto é, como inadequada ou insuficiente diante da complexidade da burocracia. Para além da recusa em aceitar o testemunho do outro como verdadeiro ou crível, o que é possível ver aqui é, conforme nos diz Hookway (2010), uma injustiça epistêmica relacionada à recusa em levar a sério a habilidade do sujeito em prover conhecimento relevante em determinado contexto. Não seria, assim, uma questão de desacreditar o outro por uma suposta desconfiança em relação 
à verdade do seu testemunho, mas uma conduta discriminatória (ainda que inconsciente) por uma suposta incompetência do sujeito (Anderson, 2012). A narrativa do solicitante de refúgio se torna, então, cada vez mais desapropriada, representando um obstáculo à sua participação ativa no processo de narrar a própria vida em documento burocrático.

Após o ritual de preenchimento do formulário de refúgio emerge a etapa fundamental da entrevista de elegibilidade. Esta prática epistêmica é compreendida pelos sujeitos como uma investigação que busca "extrair informações", "mapear" e "penetrar" os solicitantes de refúgio em busca da verdade. Para Carlos, coordenador do CONARE, a entrevista "é como uma investigação da vida da pessoa, vamos dizer que é uma conversa com formalidades". Ao me contar sobre a dinâmica das entrevistas conduzidas pelos oficiais de elegibilidade, o coordenador do Comitê afirma que, após as apresentações e explicações sobre o processo, o oficial de elegibilidade "parte para a investigação do que era, como era a vida do solicitante no país de origem".

Segundo Tatiana, oficial de elegibilidade, o importante é "saber quem é essa pessoa que estamos entrevistando". Para isso, seria preciso, nas palavras dela, "extrair informações, entender como ele se expressa, mapear a pessoa que estamos investigando". Novamente nos deparamos não com uma prática de troca testemunhal, aberta à transmissão do conhecimento pelo outro, mas com uma prática investigativa, com uma postura de "penetração" da pessoa. O solicitante é visto não como um sujeito de conhecimento, mas como investigado.

Esta perspectiva também foi compartilhada por representantes da sociedade civil no CONARE. Ao ser questionado sobre a existência de um perfil ideal de entrevistador, Júlio, da Cáritas-Rio, compara o oficial de elegibilidade à figura de um médico ou advogado:

[...] Esse perfil que eu estou falando, se você pensar, o médico, o advogado, boa parte da ação positiva do médico para chegar a um diagnóstico, um advogado entender como vai defender, é preciso que ele penetre um pouco na pessoa, que ele sinta, que ele seja partícipe, que ele se envolva, não o envolvimento do ponto de vista de tomar partido de situações e tal, mas no sentido de perceber exatamente qual é, o que está por dentro da pessoa, no caso do refugiado, o fundado temor. (Júlio, Cáritas-Rio, grifo meu)

A perspectiva investigativa norteia o imaginário de diferentes atores envolvidos no processo de elegibilidade, expressando o que Facundo (2017, p. 242) chama de necessidade de "cavar, extrair e verificar, como ações que permitiriam chegar ao mais profundo da pessoa, em uma espécie de trabalho arqueológico que faria emergir o que está dentro dele". A imagem da entrevista como prática investigativa diminui, porém, a relevância da contribuição do solicitante enquanto sujeito de conhecimento, menosprezando a sua 
participação ativa na troca testemunhal e instaurando a posição passiva do investigado. As entrevistas são estabelecidas, então, como uma prática em que o oficial detém implicitamente uma posição de autoridade que o torna encarregado de avaliar posturas, sentimentos, credibilidade interna e plausibilidade das narrativas. Não é questionado, assim, o lugar de privilégio epistêmico (Medina, 2011) do entrevistador, nem sua suposta capacidade de saber "o que está por dentro da pessoa", conforme me disse o funcionário da Cáritas-Rio.

A concepção das entrevistas como práticas investigativas, e não voltadas à transmissão do conhecimento dos solicitantes de refúgio, abre espaço para o apagamento do papel do oficial em atribuir ou não credibilidade ao que é narrado e ao solicitante. Dessa maneira, haveria um afastamento da noção da análise de credibilidade como uma prática que depende de uma comparação e contraste entre os atores envolvidos na troca testemunhal. Em outras palavras, diminui-se a relevância do caráter comparativo e da natureza de contraste de reconhecer alguém como crível ou não, deixando de lado o fato de que, conforme nos diz Medina (2011), qualquer déficit de credibilidade em relação ao testemunho de um sujeito é operado através da autoridade epistêmica ${ }^{8}$ implicitamente atribuída àquele que investiga ou questiona. Para que seja possível estabelecer a crítica ao modo como análises de credibilidade são conduzidas, com a possibilidade de produção de uma injustiça epistêmica, é preciso ter em mente as relações desiguais que atravessam o processo, relegando o solicitante à posição passiva de investigado e os oficiais ao papel epistemicamente privilegiado (Medina, 2011) de revelar as verdades contidas nos sujeitos.

As relações desiguais que atravessam e constituem o refúgio por elegibilidade no Brasil tornam-se ainda mais evidentes ao analisarmos a distinção realizada entre a força e a fraqueza dos casos. No universo brasileiro da elegibilidade, é comum ouvir os atores se referirem à credibilidade das solicitações de refúgio através das expressões "caso forte" e "caso fraco". Durante as entrevistas, esta distinção emergiu das falas de diversos sujeitos sobre se um caso "vale à pena" ser defendido pela instituição nos espaços coletivos de discussão e decisão.

Grande parte dos entrevistados não soube explicar os critérios utilizados para determinação da força ou fraqueza de uma solicitação de refúgio e, portanto, para as próprias análises de credibilidade. Ainda que eu tenha buscado repetir meus questionamentos aos entrevistados sobre como eles

8 Medina (2011) utiliza a expressão "autoridade epistêmica" como sinônima da posição de privilégio epistêmico desfrutada por aqueles sujeitos que recebem um excesso de credibilidade não-merecido. 
desenvolviam seus critérios de avaliação dos casos que "valem a pena ser defendidos", as respostas normalmente oscilaram entre "ter precedentes" e "sentir" que é um caso autêntico de refúgio. Ao questionar Beatriz, da CáritasRio, sobre a dinâmica das entrevistas na instituição, ela me contou que "muitas histórias eram muitas vezes histórias que a gente tinha percepção de que seria difícil uma avaliação como uma necessidade de proteção real, então histórias que muitas vezes pareciam histórias de migração econômica".

Quando questionada a respeito dos critérios utilizados para determinar a credibilidade de um solicitante e sua história, Maria, da Cáritas-Rio, afirmou que "tem um pouco de feeling, mas tem também a questão dos precedentes. A gente sabe mais ou menos quais são os tipos de casos que são com mais frequência deferidos e os que são com mais frequência indeferidos". O sentimento em relação aos casos vai ganhando, então, um espaço crucial nos processos desenvolvidos nesta instituição representante da sociedade civil no CONARE9. Maria me contou como sua percepção sobre as "histórias de refúgio" orientava, por exemplo, a necessidade de desenvolver novas e aprofundadas pesquisas para ajudar o advogado a defender a solicitação nos espaços coletivos do Comitê. Assim, segundo ela, quando o funcionário da Cáritas-Rio se depara com um caso e "sente que vale a pena ser defendido, é criado um memorial de defesa".

Uma parte fundamental da atuação da sociedade civil, através da CáritasRio, no CONARE parece acontecer, então, a partir da distinção entre casos fortes e fracos. Conforme emergiu da fala dos entrevistados, tal distinção pode ser baseada tanto em precedentes quanto em um feeling dos atores sobre as solicitações de refúgio, trazendo à tona o papel fundamental das percepções subjetivas nas análises de credibilidade. O papel de tais aspectos subjetivos também permite que levemos em conta, com Origgi (2012), a importância de outros mecanismos que predispõem ou influenciam as análises de credibilidade. Nesse sentido, um déficit de credibilidade poderia ser atribuído não apenas com base em preconceitos e estereótipos, mas também a partir de reações emocionais aos sujeitos e suas narrativas, produzindo um quadro de injustiça epistêmica testemunhal.

Apesar do papel dos aspectos subjetivos no processo, a atuação dos membros do Comitê nas reuniões do GEP foi descrita a partir da imagem racional e objetiva dos "técnicos do refúgio" em debate sobre argumentos para

9 Cabe salientar aqui que, sendo o CONARE um órgão multiministerial, o papel da Cáritas-Rio nas deliberações finais sobre os casos não pôde ser avaliado. Dessa maneira, o trabalho pouco tem a contribuir sobre o peso das práticas de determinação da força ou fraqueza dos casos nas decisões finais. Tal avaliação necessitaria, ainda, da possibilidade de condução de pesquisas a partir da participação nas reuniões deliberativas do Comitê e, portanto, do acesso transparente à atuação do órgão. 
o deferimento ou indeferimento das solicitações. Conforme me contou José, da Cáritas-SP, enquanto na plenária "entra mais o elemento político", no GEP "é uma discussão técnica, a função do GEP é a discussão técnica sobre os casos, óbvio, mas também sobre como os casos são decididos e como eles são analisados". O caráter "técnico" do grupo reforça o papel epistemicamente privilegiado de avaliar os testemunhos dos sujeitos que é atribuído aos "técnicos do refúgio". Em virtude de treinamentos e suposta expertise no tema, os entrevistados percebem as reuniões do GEP como legítimas e necessárias para que as decisões sejam tomadas "com alguma lucidez", tendo em vista a "profundidade do debate que ocorre no âmbito do Grupo de Estudos Prévios", conforme me contou o funcionário da Cáritas-SP.

O privilégio epistêmico dos membros do Comitê, inclusive do representante da sociedade civil no órgão, ficaria evidenciado, assim, "no papel epistemicamente privilegiado de receber, avaliar e decidir sobre testemunhos e interpretações" (Carel, Kidd, 2014, p. 16). Nas práticas de privilegiar determinadas posições epistêmicas, um excesso de credibilidade é dado aos sujeitos capazes de fazer julgamentos sobre os testemunhos e decidir seu caráter de verdade. Este cenário importa para a possibilidade de produção de injustiça epistêmica, uma vez que "excessos de credibilidade podem aparecer como uma forma de privilégio epistêmico imerecido que é crucialmente relevante para questões de justiça testemunhal" (Medina, 2011, p. 15). Nesse sentido, e segundo Medina, um excesso de credibilidade pode constituir uma injustiça epistêmica já que concede a determinados sujeitos uma condição imerecida de privilégio epistêmico. O grupo de membros do Comitê capazes de saber por uma suposta expertise detém, assim, a legitimidade para o argumento técnico sobre as verdades da condição refugiada.

Apesar da imagem da racionalidade e objetividade das argumentações, o papel dos aspectos subjetivos permanece vindo à tona na fala dos atores responsáveis pelas decisões na plenária do Comitê. Ao relatar a dificuldade que sente na tomada de decisões, Júlio, da Cáritas-Rio, expõe o caráter subjetivo que fornece as bases para a decisão sobre a concessão ou não do status de refugiado ao solicitante. Questionado sobre a subjetividade das decisões, que pode estar refletida em casos similares com pareceres diferentes, o entrevistado afirma que é normal que ocorra esta discrepância e acrescenta: "uma mesma história, dois finais". Quando perguntei a respeito das dinâmicas nas reuniões decisórias do Comitê, Júlio voltou a enfatizar o papel de aspectos subjetivos no processo:

Na discussão às vezes a gente pede para refazer a entrevista, para aprofundar mais, pede opinião do ACNUR, ou pede relatório do Itamaraty, sobre determinadas regiões, pesquisa sobre acontecimentos dos países de origem, informação da Anistia... e têm muitos casos, assim, às vezes é o dia inteiro, só ler o caso, ouvir 
entrevista, perguntar de novo, às vezes chama o assistente de proteção para falar, dizer qual foi o sentimento. (Júlio, Cáritas-Rio, grifo meu)

A imagem do caráter subjetivo do processo de elegibilidade fica ainda mais evidente a partir da fala que destaquei acima, que aponta as dificuldades para a concessão do refúgio e a permanência das dúvidas e questionamentos mesmo após a decisão já ter sido tomada. Ao me contar que buscava "ver quem era a pessoa e conversar um pouco... qualquer coisa para sentir", Júlio traz à tona o fato de que, conforme afirma Origgi (2012), uma economia da credibilidade é profundamente marcada por diferentes estratégias cognitivas que ajudam a distribuir a confiança de maneiras desiguais entre os participantes de uma troca testemunhal. A partir disso, torna-se crucial ter em mente a possibilidade de produção de uma injustiça epistêmica que impede a participação dos solicitantes de refúgio como sujeitos do conhecimento, enquanto membros do CONARE tomam como base suas emoções para julgar a credibilidade dos testemunhos.

No que diz respeito à existência de precedentes na determinação da força ou fraqueza dos casos, bem como ao papel do conhecimento técnico e do feeling baseado em experiências dos sujeitos responsáveis pelas avaliações de credibilidade, é preciso salientar aqui sua possível contribuição ao reforço de estereótipos e preconceitos no processo de elegibilidade. Conforme nos diz Jubany, em análise realizada desde a realidade do Reino Unido, os critérios utilizados pelos oficiais para avaliar os solicitantes de refúgio não são propriamente derivados de regulamentos ou leis, mas das próprias categorizações dos sujeitos e de valores que "derivam de estereótipos ambíguos nutridos pelas experiências dos oficiais e seus preconceitos sociais" (Jubany, 2011 , p. 2). Os oficiais podem fazer uso de sua experiência e "expertise" para decidir as verdades do refúgio, aplicando "sua subjetividade sem nenhuma outra justificativa além de uma série de preconceitos determinados pelo grupo" (Jubany, p. 15). Nesse sentido, a articulação entre precedentes, conhecimento técnico e feeling baseados nas experiências dos sujeitos pode reforçar a imagem de que a 'intuição ou instinto profissional', para usar termos da própria Jubany, seria suficiente para determinar a credibilidade dos solicitantes de refúgio.

Com isso não busco afirmar aqui, de maneira simplória, que tudo pode ser resumido à injustiça epistêmica. Em outras palavras, ainda seria preciso determinar, por exemplo, em quais casos o recurso ao conhecimento técnico - ou mesmo ao 'instinto profissional' - poderia contribuir para fortalecer a solicitação de refúgio ao produzir intervenções no processo que beneficiariam o solicitante. A exploração das ambivalências existentes nas práticas da elegibilidade permanece, assim, tópico fundamental para análise, sem excluir a importância de reflexões sobre a reprodução de injustiças epistêmicas - ao passo que reforça a necessidade de transparência da atuação do CONARE e da abertura do processo aos pesquisadores e seus estudos etnográficos. A emergência 
de uma série de questionamentos a respeito das dinâmicas do processo, do impacto das narrativas dos solicitantes nas análises de credibilidade e do papel das intervenções que se pretendem técnicas no auxílio aos deferimentos, para nomear apenas alguns, traz à tona a existência de lacunas que a presente análise não pode - e não pretende - ter sucesso em responder. Reafirmo, dessa maneira, a relevância de dar início ao debate sobre questões de (in)justiça nos processos de elegibilidade, abrindo caminho para análises posteriores que ajudem na reflexão sobre práticas complexas e ambivalentes que possuem impacto fundamental sobre as vidas dos solicitantes e refugiados no Brasil.

\section{Considerações Finais}

Procurei ressaltar aqui um cenário complexo em que a participação dos solicitantes de refúgio no processo de elegibilidade encontra uma série de obstáculos, afetando as práticas epistêmicas de transmissão do conhecimento por parte destes sujeitos, cada vez mais relegados à posição passiva de investigados ${ }^{10}$. Conforme a definição de injustiça epistêmica proposta por Fricker (2007) nos diz, é preciso lançar luz sobre a produção de injustiças que afetam a capacidade de alguém enquanto um sujeito do conhecimento. Além disso, a atuação de preconceitos sobre a dimensão da competência dos solicitantes, bem como o papel de aspectos subjetivos nos julgamentos de credibilidade podem ser vistos como elementos relevantes para a produção de injustiças epistêmicas testemunhais, enquanto uma posição de privilégio epistêmico (Medina, 2011) dos "técnicos do refúgio" é mantida.

Entretanto, é preciso abrir espaço para considerar o caráter ambivalente na atuação da sociedade civil neste cenário. Ainda que a ênfase das análises esteja localizada sobre a possibilidade de produção de injustiças epistêmicas, é preciso ter em mente a complexidade do processo e a tentativa, por parte da sociedade civil, de aumentar as chances de sucesso das solicitações. Nesse sentido, seja o esforço de orientação para o preenchimento do formulário, seja a busca por defender casos que tenham mais chances no CONARE, por exemplo, também podem ser compreendidos do ponto de vista de uma busca pelo deferimento das solicitações. Entretanto, a ambivalência e a complexidade dos processos não diminuem a relevância de uma reflexão sobre como o refúgio por elegibilidade pode evidenciar um processo que se construiu, estruturalmente e formalmente, de modo a facilitar a reprodução de injustiças epistêmicas através das práticas de determinação do status de refugiado ${ }^{11}$.

${ }^{10}$ Conforme vimos, ainda que o processo tenha início a partir do convite ao compartilhamento da narrativa do solicitante sobre sua própria vida e história pregressa de perseguição, a dinâmica prossegue com a diminuição deste espaço em favor de uma postura investigativa por parte dos atores responsáveis pela avaliação de credibilidade.

11 Embora não seja interessante desenvolver uma discussão sobre culpabilidade, cabe ressaltar aqui que o recorte da análise sobre a atuação da sociedade civil não exclui a importância de 
Há, dessa maneira, uma ambivalência que parece refletir a própria dificuldade de atuação em um sistema no qual uma instituição representante da sociedade civil busca, ao mesmo tempo, trabalhar com solicitantes e refugiados de modo a ajudá-los a diminuir sua posição de desvantagem e, ainda, compor a própria estrutura decisória que (re) produz injustiças ao determinar a concessão do status através dos julgamentos de credibilidade. A busca por explorar e discutir a reprodução de injustiças neste processo pode abrir caminho, então, para reflexões direcionadas à possibilidade de produção de formas de justiça epistêmica. Reconsiderar questões de justiça no processo brasileiro de elegibilidade significaria, dessa maneira, mudar os rumos do debate em direção à importância do desenvolvimento de consciências críticas reflexivas e ao questionamento da própria estrutura da elegibilidade. Em outras palavras, questionar as práticas epistêmicas pelas quais o status de refugiado é determinado no Brasil é apenas o primeiro passo em direção a novos debates sobre o que seria um processo justo - e como alcançá-lo.

\section{- Nota de agradecimento -}

O presente artigo beneficiou-se imensamente das contribuições de alguns sujeitos. Agradeço aos revisores anônimos da revista pelos comentários e críticas produtivas. Sou grata à Carolina Moulin Aguiar pela orientação durante a pesquisa de doutorado e pelo apoio sem medida. Agradeço, especialmente, àqueles que encontrei durante o trabalho de campo pelo tempo e energia investidos nas entrevistas. Embora eu assuma a inteira responsabilidade pela análise aqui desenvolvida, espero que saibam que procurei tratar com respeito e consideração as diferentes perspectivas e experiências compartilhadas comigo.

\section{Referências bibliográficas}

ALCOFF, Linda. Epistemic Identities. Episteme, v. 7, n. 2, p. 128-137, 2010.

ALEXANDER, Michael. Refugee Status Determination Conducted by UNCHR. International Journal of Refugee Law, v. 11, n. 2, p. 251-289, 1999.

ANDERSON, Elizabeth. Epistemic Justice as a Virtue of Social Institutions. Social Epistemology: A Journal of Knowledge, Culture and Policy, v. 26, n. 2, p. 163-173, 2012.

BAILEY, Alison. On Anger, Silence, and Epistemic Injustice. Royal Institute of Philosophy Supplement, v. 84, p. 93-115, 2018.

CAMERON, Hilary. Refugee Status Determination and the Limits of Memory. International Journal of Refugee Law, v. 22, n. 4, p. 469-511, 2010.

CAREL, Havi; KIDD, Ian James. Epistemic Injustice in Healthcare: A philosophical Analysis. Medicine Health Care and Philosophy, v. 17, n. 4, p. 529-540, 2014. 
COHEN, Juliet. Questions of Credibility: Omissions, Discrepancies and Errors of Recall in the Testimony of Asylum Seekers. International Journal of Refugee Law, v. 13, n. 3, p. 293-309, 2001.

DOTSON, Kristie. Tracking Epistemic Violence, Tracking Practices of Silencing. Hypatia, v. 26, n. 2, p. 236-257, 2011.

FACUNDO, Angela. Exxodos, Refúgios e Exílios. Colombianos no Sul e Sudeste do Brasil. Rio de Janeiro: Papeis Selvagens, 2017.

FRICKER, Miranda. Epistemic Oppression and Epistemic Privilege. Canadian Journal of Philosophy, v. 29, n. 1, p. 191-210, 1999.

FRICKER, Miranda. Epistemic Injustice and a Role for Virtue in the Politics of Knowing. Metaphilosophy, v. 34, n. 1-2, p. 153-173, 2003.

FRICKER, Miranda. Powerlessness and Social Interpretation. Episteme: A Journal of Social Epistemology, v. 3, n. 1-2, p. 96-108, 2006.

FRICKER, Miranda. Epistemic Injustice. Power \& the Ethics of Knowing. Nova lorque: Oxford University Press, 2007.

FRICKER, Miranda. Replies to Critics. Theoria, v. 23, n. 61, p. 81-86, 2008.

FRICKER, Miranda. Replies to Alcoff, Goldberg, and Hookway on Epistemic Injustice. Episteme: A Journal of Social Epistemology, v. 7, n. 2, p. 164-178, 2010.

GIBB, Robert; GOOD, Anthony. Interpretation, Translation and Intercultural Communication in Refugee Status Determination Procedures in the UK and France. Language and Intercultural Communication, v. 14, n. 3, p. 385-399, 2014. GOOD, Anthony. Anthropology and Expertise in the Asylum Courts. Londres: Routledge-Cavendish, 2007.

GORLICK, Brian. Common Burdens and Standards: Legal Elements in Assessing Claims to Refugee Status. New Issues in Refugee Research, Working Paper, n. 68, p. 1-17, 2002.

GRIFFITHS, Melanie. Vile Liars and Truth Distorters. Truth, Trust and the Asylum System. Anthropology Today, v. 28, n. 5, p. 8-12, 2012.

HHC - Hungarian Helsinki Committee. Credibility Assessment in Asylum Procedures. Budapeste: Hulgarian Helsinki Committee, 2013. Disponível em: <http://www. helsinki.hu/en/credibility-assessment-in-asylum-procedures-a-multidisciplinarytraining-manual/> . Acesso em: 18.06.2017.

HOOKWAY, Christopher. Some Varieties of Epistemic Injustice: Reflections on Fricker. Episteme, v. 7, n. 2, p. 151-163, 2010.

JENSEN, Katherine. The Epistemic Logic of Asylum Screening: (dis)Embodiment and the Production of Asylum Knowledge in Brazil. Ethnic and Racial Studies, v. 41, n. 15, p. 2615-2633, 2018.

JUBANY, Olga. Constructing Truths in a Culture of Disbelief: Understanding Asylum Screening from Within. International Sociology, v. 26, n. 1, p. 74-94, 2011.

JUBILUT, Liliana. Direito internacional dos refugiados e sua aplicação no ordenamento jurídico brasileiro. São Paulo: Método, 2007. 
KAGAN, Michael. Is Truth in the Eye of the Beholder? Objective Credibility Assessment in Refugee Status Determination. Scholarly Works. Paper 633, 2003. Disponível em: <http://scholars.law.unlv.edu/facpub/633/>. Acesso em: 25.06.2017.

KAGAN, Michael. The Beleaguered Gatekeeper: Protection Challenges Posed by UNHCR Refugee Status Determination. Scholarly Works, Paper 636, 2006. Disponível em: <http://scholars.law.unlv.edu/facpub/636/>. Acesso em: 25.06.2017.

KWONG, Jack. Epistemic Injustice and Open-Mindedness. Hypatia, v. 30, n. 2, p. 337-351, 2015.

MAGALHÃES, Bruno. Enacting Refugees: An Ethnography of Asylum Decisions (Tese de doutorado). The Open University, Departamento de Política e Relações Internacionais, Londres, 2014.

MAGALHÃES, Bruno. The Politics of Credibility: Assembling Decisions on Asylum Applications in Brazil. International Political Sociology, v. 10, p. 133-149, 2016.

MARSH, Gerald. Trust, Testimony and Prejudice in the Credibility Economy. Hypatia, v. 26, n. 2, p. 280-293, 2011.

MEDINA, José. The Relevance of Credibility Excess in a Proportional View of Epistemic Injustice: Differential Epistemic Authority and the Social Imaginary. Social Epistemology, v. 25, n. 1, p. 15-35, 2011.

ORIGGI, Gloria. Is Trust an Epistemological Notion? Episteme, v. 1, n. 1, p. 61-72, 2004.

ORIGGI, Gloria. Epistemic Injustice and Epistemic Trust. Social Epistemology, v. 26, n. 2, p. 221-235, 2012.

RIGGS, Wayne. Open-Mindedness. Methaphilosophy, v. 41, n. 1-2, p. 172-188, 2010.

RIGGS, Wayne. Culpability for Epistemic Injustice. Social Epistemology, v. 26, n. 2, p. 149-162, 2012.

ROUSSEAU et alii. The Complexity of Determining Refugeehood: A Multidisciplinary Analysis of the Decision-Making Process of the Canadian Immigration and Refugee Board. Journal of Refugee Studies, v. 15, n. 1, p. 43-70, 2002.

SALES, Rosemary. The Deserving and the Undeserving? Refugees, Asylum Seekers and Welfare in Britain. Critical Social Policy, v. 22, n. 3, p. 456-478, 2002.

SALTSMAN, Adam. Beyond the Law: Power, Discretion and Bureaucracy in the Management of Asylum Space in Thailand. Journal of Refugee Studies, v. 27, n. 3, p. 457-476, 2014.

SOUTER, James. A Culture of Disbelief or Denial? Oxford Monitor of Forced Migration, v. 1, n. 1, p. 48-59, 2011.

SWEENEY, James. Credibility, Proof and Refugee Law. International Journal of Refugee Law, v. 21, n. 4, p. 700-726, 2009.

WESTON, Amanda. A Witness of Truth - Credibility Findings in Asylum Appeals. Immigration \& Nationality Law \& Practice, v. 12, n. 3, p. 87-89, 1998. 